\title{
Effect of Location of Genioplasty Osteotomy Line on Hard- and Soft-Tissue Contour of the Chin and Related Complications
}

\author{
Nima Dehghani ${ }^{1}$, Hooshyar Abbasi $^{2}$, Osame Heidari ${ }^{3}$, Mohammad Moslem Imani ${ }^{4 *}$ \\ ${ }^{1}$ Department of Oral and Maxillofacial Surgery, Dental School, Tehran University of Medical Sciences, Tehran, Iran; ${ }^{2}$ Department \\ of Oral and Maxillofacial Surgery, Kermanshah University of Medical Sciences, Kermanshah, Iran; ${ }^{3}$ Students Research \\ Committee, Kermanshah University of Medical Sciences, Kermanshah, Iran; ${ }^{4}$ Department of Orthodontics, School of Dentistry, \\ Kermanshah University of Medical Sciences, Kermanshah, Iran
}

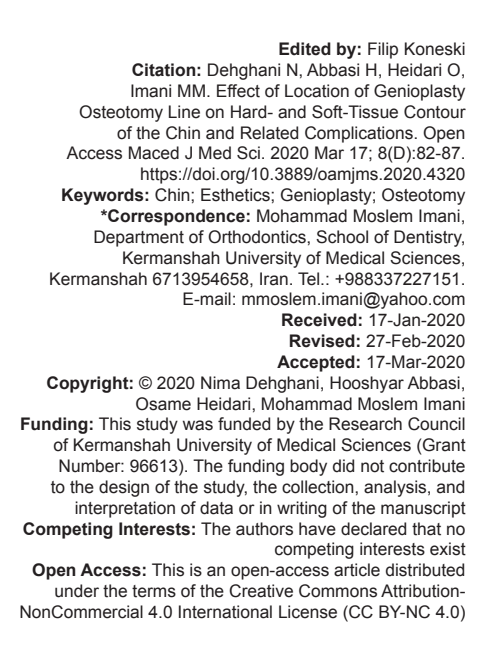

Abstract

AIM: This study aimed to assess the effect of the location of the genioplasty osteotomy line on hard- and soft-tissue contour of the chin and the occurrence of irregularity in the inferior border of the mandible.

METHODS: In this retrospective cohort study, 20 patients who had undergone osseous genioplasty were divided into two groups with $(A)$ osteotomy line at the premolar site and $(B)$ osteotomy line at the molar site and were evaluated for irregularity in the inferior border of the mandible. Assessments were made using lateral cephalometry, panoramic radiography, and clinical examinations. Patients were also asked about their level of satisfaction with the outcome.

RESULTS: Radiographically, $70 \%$ of patients in Group A and $40 \%$ of those in Group B had an irregularity in the inferior border of the mandible ( $p>0.05$ ). Palpation revealed that $70 \%$ in Group A and $60 \%$ in Group B had an irregularity in the inferior border of the mandible $(p>0.05)$. Inspection revealed such irregularity in $80 \%$ of patients in Group A and 20\% in Group B ( $p<0.05$ ). Overall, $60 \%$ in Group A and $90 \%$ in Group B were satisfied with the results of genioplasty and did not mention anything about the occurrence of this complication $(p>0.05)$.

CONCLUSIONS: Genioplasty with an osteotomy line at the molar site (compared to premolar site) had a lower incidence of the irregularity of the inferior border of the mandible and yielded higher patient satisfaction with the outcome.

PRACTICAL IMPLICATIONS: Irregularity in the inferior border of mandible following conventional genioplasty is a common finding on radiographic and clinical examinations.

\section{Introduction}

Facial esthetics depends on the form, proportionality, and position of different components of the face. The chin is the most important part of the face in terms of esthetics in both the frontal and profile views [1], [2]. However, chin deformity may occur due to trauma, congenital anomalies, or developmental defects [3]. Surgical correction of chin deformity was first attempted in the early $20^{\text {th }}$ century. Hofer was the first to introduce sliding osseous genioplasty in 1942 [4]. He used the extraoral submental approach for this purpose. A few years later, some others performed intraoral horizontal osteotomy of the chin, and this technique replaced the extraoral approach [5], [6], [7], [8]. Osseous genioplasty is a commonly practiced cosmetic surgery with profound effects on facial harmony and esthetics, especially in the lower third of the face [9]. Many authors have discussed that osseous genioplasty can be applied for correction of most cases of chin deformity, while prosthetic genioplasty is often used to correct mild retrognathia. On the other hand, osseous genioplasty can fix the chin deformity in all three spatial dimensions. It enables lengthening and shortening of the chin, forward and backward movement of the chin, its lateral movement, and its rotation. Despite the numerous advantages of osseous genioplasty, correction of the contour and irregularities of the inferior border of mandible with prosthetic genioplasty would be easier. In brief, it may be stated that osseous genioplasty is recommended for most patients, especially those with severe or complex deformities requiring several surgical steps. In contrast, correction of the chin with prosthetic genioplasty is mainly limited to mild or moderate retrognathia and correction of the shape and contour of the chin [1], [8], [10], [11], [12], [13]. Despite the fact that osseous genioplasty is a flexible and easy approach with extensive indications, it can have complications such as the creation of irregularity in the inferior border of the mandible, which can result in the unesthetic appearance of the soft tissue of the chin. The risk of this complication is higher in osseous genioplasty compared to prosthetic genioplasty and in severe cases; it can compromise the esthetics of the soft tissue of the chin [1]. Several surgical 
techniques have been proposed for osseous genioplasty, each having advantages and disadvantages; of all, two approaches with osteotomy lines at the premolar and molar sites are more popular than other techniques [3].

However, studies on the incidence of irregularities in the inferior border of mandible following osseous genioplasty are limited, and the effects of location of an osteotomy line in genioplasty on the soft- and hard-tissue contour of the chin and related complications have not been evaluated. Therefore, this study aimed to assess the effect of osteotomy line at the molar and premolar sites on the rate of complications and esthetic outcome of surgery in terms of irregularity in the inferior border of the mandible to find the best approach for achieving the best esthetic results.

\section{Materials and Methods}

This retrospective cohort study was performed on patients who underwent osseous genioplasty in Kermanshah hospitals from 2016 to 2017. The study was approved by the ethics committee of Kermanshah University of Medical Sciences (IR.KUMS. REC.1396.397). Of all, only patients who underwent advancement osseous genioplasty were evaluated. A minimum of 6 months had to be passed since their surgical operation for adequate bone healing [7], [14]. Patients were selected using convenience sampling.

Patients who had undergone osseous genioplasty were recalled for periodic examinations. According to the information available inpatient files and panoramic radiographs and lateral cephalograms of patients, they were categorized into two groups of $(A)$ genioplasty with osteotomy line at the premolar site and (B) genioplasty with osteotomy line at the molar site. For genioplasty, an incision was made in the inferior labial vestibular mucosa of the mandible. The osteotomy cut was extended from the symphyseal midline to the inferior border of mandible below the premolar site and mental nerve in Group A and to the molar site in Group B. The cut was made by a surgical saw while maintaining a $5 \mathrm{~mm}$ distance from the apex of roots of mandibular incisors and mental nerve. The separated distal segment of chin bone (which was still attached to genioglossus and geniohyoid muscles) was fixed in a more anterior position as required. Eventually, the inferior border of mandible was palpated to ensure a smooth border. Two cuts were made in the mandible of each patient, and the esthetic results of each cut were evaluated.

\section{Inclusion criteria}

The following criteria were included in the study:

- $\quad$ Patients who had undergone advancement osseous genioplasty
Absence of congenital deformities or disorders Absence of skeletal and metabolic diseases

Absence of pathologic lesions

At least 6 months had to be passed since their surgical operation for adequate bone healing [7], [14].

Radiographic assessments to find irregularity of the inferior border of the mandible were performed in two groups using panoramic radiography and lateral cephalometry. Radiographs were inspected on a negatoscope and the continuity of the inferior border of the mandible from the gonial notch to gonion was evaluated. Patients in whom this continuity was disrupted by a step or notch were categorized as having the irregular border of mandible radiographically; otherwise, they were categorized as normal (Figure 1).

The presence of a step or notch in the inferior border of mandible was also evaluated by a surgeon through clinical palpation of the osteotomy site. In the case of finding a depression in the hard tissue contour, it was considered as the presence of irregularity in the inferior border of the mandible. The presence of a smooth contour was considered normal. These findings were also compared with pre-operative photographs.

Patients were also asked about their satisfaction with the treatment results and continuity and smoothness of the inferior border of the mandible. They were requested to palpate the inferior border of their mandible and report if they felt any irregularity on palpation or noticed it after accurate inspection. In the case of reporting it, it was considered an abnormal finding. If the irregularity was present, but the patient did not notice it, or in case of its absence, the case was considered to be normal.

Other possible complications such as paresthesia of the chin and all types of tooth injures such as root fracture (cut by bur or saw), tooth necrosis, and tooth mobility were also evaluated in this study.

Normal distribution of data was evaluated using the Kolmogorov-Smirnov test. Since data were found to be normally distributed ( $p>0.1)$, independent samples t-test was used to compare quantitative variables between the two groups. Chi-square test, Monte Carlo Chi-square test, and Fisher's exact test were used to assess the correlation of qualitative variables with study groups. The collected data were analyzed using SPSS version 18 (SPSS Inc., IL, USA). The level of significance was set at 0.05 .

\section{Results}

There were 3 males (15\%) and 17 females $(85 \%)$ in the study. The mean age of patients was $24.05 \pm 3.25$ years. There were $8(80 \%)$ females and $2(20 \%)$ males in Group A and 9 females (90\%) and 


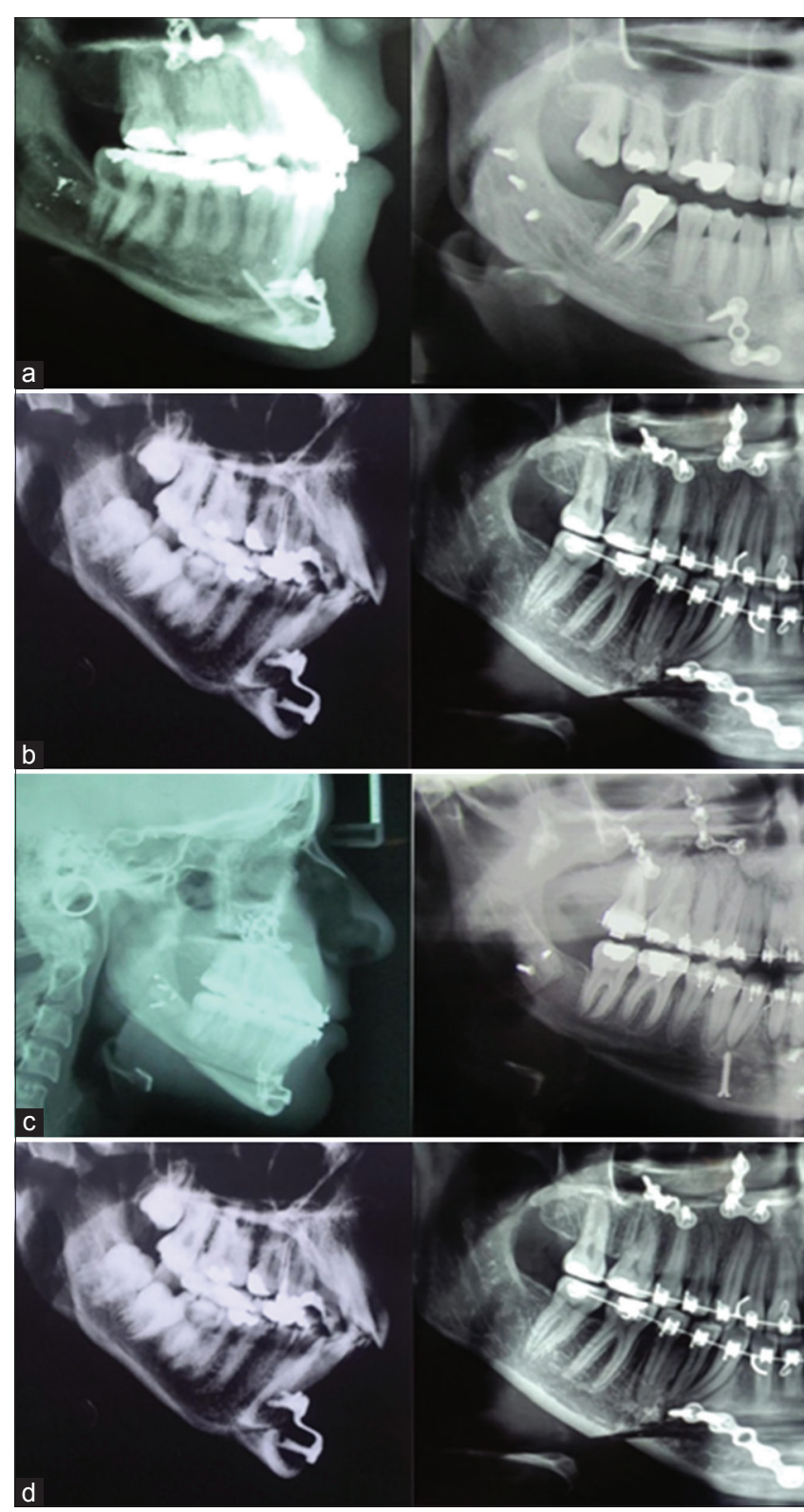

Figure 1: Genioplasty. (a) A patient in Group A for whom, genioplasty was performed with osteotomy at the site of premolar tooth and did not have irregularity of the inferior border of mandible. (b) A patient in Group A for whom, genioplasty was performed with osteotomy at the site of premolar tooth and developed irregularity of the inferior border of the mandible. (c) A patient in Group B for whom, genioplasty was performed with osteotomy at the site of molar tooth and did not have irregularity of the inferior border of mandible. (d) A patient in Group $B$ for whom, genioplasty was performed with an osteotomy at the site of molar tooth and developed irregularity of the inferior border of the mandible

one male (10\%) in Group B. No significant association existed between the type of surgical approach and gender (Fisher's exact test, $p=1.00$ ).

Table 1 compares age, follow-up time, and the magnitude of chin advancement in the two groups. The two groups were not significantly different in terms of mean age (independent samples t-test; $p=0.09$ ), follow-up time (independent samples t-test, $p=0.65$ ), or the magnitude of chin advancement (independent samples t-test, $p=0.54$ ).
Table 1: Age, follow-up time, and magnitude of chin advancement in the two groups

\begin{tabular}{|c|c|c|c|c|c|}
\hline & \multicolumn{4}{|l|}{ Group } & \multirow[t]{3}{*}{$p$-value } \\
\hline & \multicolumn{2}{|c|}{$\begin{array}{l}\text { Osteotomy line in } \\
\text { premolar region }\end{array}$} & \multicolumn{2}{|c|}{$\begin{array}{l}\text { Osteotomy line in } \\
\text { molar region }\end{array}$} & \\
\hline & Mean & $\begin{array}{l}\text { Standard } \\
\text { deviation }\end{array}$ & Mean & $\begin{array}{l}\text { Standard } \\
\text { deviation }\end{array}$ & \\
\hline Age & 22.80 & 3.55 & 25.30 & 2.50 & 0.085 \\
\hline Follow-up term (months) & 8.10 & 2.42 & 7.60 & 2.41 & 0.649 \\
\hline Advancement amount (mm) & 4.80 & 1.14 & 5.10 & 0.99 & 0.538 \\
\hline
\end{tabular}

Table 2 shows the frequency of patients in terms of surgical procedures received. No significant correlation was found between the type of surgical procedure and association with other procedures (Monte Carlo Chi-square test, $p=0.81$ ). Root fracture did not occur in any case.

Table 2: Frequency of patients in terms of the type of surgical procedures received

\begin{tabular}{|c|c|c|c|c|}
\hline & \multicolumn{4}{|l|}{ Group } \\
\hline & \multicolumn{2}{|c|}{$\begin{array}{l}\text { Osteotomy line in the } \\
\text { premolar region }\end{array}$} & \multicolumn{2}{|c|}{$\begin{array}{l}\text { Osteotomy line in the } \\
\text { molar region }\end{array}$} \\
\hline & Count & Column $\mathrm{n} \%$ & Count & Column $\mathrm{n} \%$ \\
\hline \multicolumn{5}{|l|}{ Other procedures } \\
\hline Genioplasty alone & 6 & 60.0 & 4 & 40.0 \\
\hline With mandibular osteotomy & 0 & 0.0 & 0 & 0.0 \\
\hline With maxillary osteotomy & 3 & 30.0 & 5 & 50.0 \\
\hline $\begin{array}{l}\text { With maxillary and mandibular } \\
\text { osteotomy }\end{array}$ & 1 & 10.0 & 1 & 10.0 \\
\hline $\begin{array}{l}\text { Rhinoplasty and/or other } \\
\text { plastic surgeries }\end{array}$ & 0 & 0.0 & 0 & 0.0 \\
\hline
\end{tabular}

Of all, $70 \%$ of patients in Group A and $40 \%$ of patients in Group B had irregularity of the inferior border of mandible radiographically. No significant association was noted between the type of surgical approach and irregularity of the inferior border of the mandible on radiographs (Fisher's exact test, $p=0.37$ ).

Of all, $70 \%$ of patients in Group A and $60 \%$ of patients in Group B had irregularity of the inferior border of the mandible on clinical examination. No significant association was noted between the type of surgical approach and irregularity in the inferior border of the mandible on clinical examination (Fisher's exact test, $p=1.00)$.

Of all, $80 \%$ in Group A and 20\% in Group B had soft-tissue irregularity of the chin, and a significant association existed between the type of surgical approach and irregularity of the soft tissue of the chin (Chi-square, $p=0.01$ ).

Furthermore, $30 \%$ in Group A and $10 \%$ in Group B felt a step in the inferior border of their mandible on palpation. The type of surgical approach had no significant association with the patient reporting a step in the inferior border of the mandible on palpation (Fisher's exact test, $p=0.58$ ).

Of all, 40\% in Group A and 10\% in Group B noticed a step in the appearance of the inferior border of their chin. The association between the type of surgical approach and noticing a step in the appearance of the inferior border of the chin was not significant (Fisher's exact test, $p=0.30$ ). 
In Groups A and B, $10 \%$ and $20 \%$ of patients, respectively, had paresthesia of the chin. The association between the type of surgical approach and paresthesia of the chin was not significant (Fisher's exact test, $p=1.00$ ).

Figure 2 compares the frequency of different complications between the two groups.

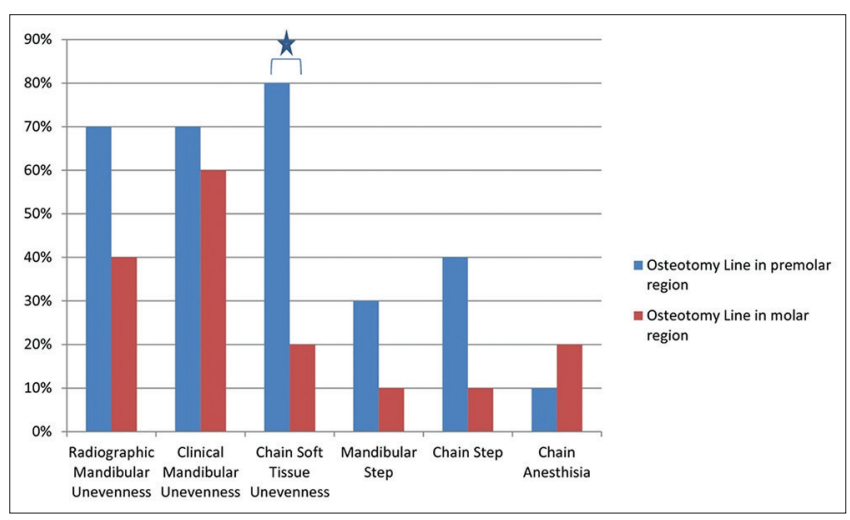

Figure 2: Comparison of frequency of different complications between the two groups. The asterisk presents a significant difference $(p<0.05)$ between two groups

\section{Discussion}

Osseous genioplasty is a commonly practiced surgical procedure to correct the form and position of the chin and improves facial symmetry and esthetics. This approach can be performed alone or combined with other facial cosmetic surgeries such as orthognathic surgery and rhinoplasty. In this study, $50 \%$ of the genioplasty procedures were associated with other surgical procedures in the face.

Genioplasty has many advantages over alloplastic implants of the chin. It enables the greater movement of the chin, has no risk of foreign body reaction or prosthesis infection, has the ability to correct the position of the chin in the vertical dimension (lengthening or shortening of the chin), and enables correction of chin asymmetry. Furthermore, chin implants may cause resorption of the underlying bone, have the risk of dislocation, and are associated with lower patient satisfaction [7], [15], [16]. If performed during adolescence, genioplasty affects the upper airway at the level of the oropharynx and can improve sleep breathing disorders [17].

Genioplasty has several complications; paresthesia of the lower lip and chin is among the most common complications of genioplasty. Lindquist and Obeid [9] reported the prevalence of this complication to be $28.5 \%$. Gui et al. [1] reported different degrees of lower lip paresthesia in the majority of patients. In our study, $20 \%$ of patients reported chin paresthesia. Gap formation between the osteotomized bone segments is another complication of osseous genioplasty, which is more prominent in cases of chin lengthening, chin advancement, and correction of chin asymmetry. This gap between the two bone segments can result in impaired bone healing and eventual formation of a palpable or observable step in the inferior border of the mandible and irregularity of chin contour.

Lindquist and Obeid [9] reported that $72.5 \%$ of patients had a notch in the inferior border of the mandible on radiographs. Kim and Steinbacher [14] reported that in two patients, the irregularity of the inferior border of the mandible was so severe that it necessitated reoperation. They reported the presence of a step on radiographs in 55\% of patients and on clinical examination in $20 \%$. To overcome this problem, one method is to use heterogeneous materials such as autogenous bone or cartilage, allograft or xenograft bone, poly-ethylene materials, or hydroxyapatite to fill the gap in bone [18], [19], [20], [21], [22], [23], [24], [25]. Deshpande et al. [26] stated that to prevent irregularity in the inferior border of the mandible, after making the osteotomy cut in the chin and fixation of segments, the inferior border of the mandible should be palpated to find the step, if present, and smoothen it with bur [26].

Since the introduction of osseous genioplasty, many techniques and approaches have been suggested to decrease complications and increase the efficacy of this procedure. In the conventional genioplasty technique, the osteotomy cut starts at the mandibular symphyseal midline bilaterally and is terminated with a mild slope at the inferior border of the mandible beneath the first or second premolar. In this approach, it is important to maintain a few millimeters space from the roots of incisor teeth and canines, as well as the mental nerve. Logically, the milder the slope of the osteotomy cut (the closer the angle), the smaller the magnitude of step in the inferior border would be. However, this factor is limited by the distance from the tooth root and mental nerve to the inferior border of the mandible.

This study assessed the effect of osteotomy cut endpoint at the two sides of molar teeth (a cut with a milder slope) and premolars on step formation in the inferior border of the mandible. The presence/absence of step was evaluated clinically and radiographically, and the patient's attention to its presence was also evaluated. In other words, this complication was evaluated both subjectively and objectively, and its clinical effects on patients were also evaluated. The results showed that the incidence of irregularity and step in the inferior border of the mandible after genioplasty was lower in both radiographic and clinical palpation by the surgeon when the osteotomy line was at the molar site; however, this difference was not significant. In clinical inspection by the surgeon, the incidence of step in the inferior border of the mandible was significantly lower in the group with osteotomy line at the molar site.

In terms of patient satisfaction with the treatment outcome and occurrence of this complication, a higher satisfaction rate and lower incidence of irregularity in the contour of the chin and the mandible 
were reported in the group with osteotomy line at the molar site; although this difference was not statistically significant. The incidence of chin paresthesia was higher in the group with the osteotomy line at the molar site, but this difference was not significant either.

Regarding the sensitivity of the methods employed to detect irregularity of the inferior border of the mandible, palpation by the surgeon revealed the highest incidence of this complication and had the highest accuracy and sensitivity for this purpose. Radiographic examination ranked second and had acceptable accuracy for this purpose as well.

Regarding the satisfaction of patients with the outcome of genioplasty and the ability to detect irregularity of the inferior border mandible, although the frequency of patient complaints about this complication was lower, this difference did not reach statistical significance. However, it was clinically important. However, it should be noted that the level of attention of patients may vary, and patients generally pay less attention to details compared to surgeons. Another important factor that can affect the clinical effects of genioplasty is its concomitance with other cosmetic procedures ( $50 \%$ of the cases in our study). In such cases, the esthetic outcome of several procedures performed concomitantly can be so drastic that impair the patient's attention to details, and irregularity of the inferior border of the mandible may only be detected if it is severe or by detail-oriented patients. Overall, the level of satisfaction of patients with the results of genioplasty was high $(75 \%)$, in our study, and was close to the value reported by Hoenig (90\%) [27].

Another important issue is the effect of this step on the soft tissue of the chin and border of the mandible. Irregularity of the inferior border of the mandible is not apparently seen in all patients whose radiographic or palpation examinations indicate the presence of a step or irregularity. Several factors play a role in this respect, such as thickness and quality of the skin and soft tissue of the chin and type of movement of bone segments. The thicker the skin and the weaker its adhesion to the underlying tissue, the less the show of step and the underlying bone irregularity would be.

The movement of bone segments such as advancement, lengthening, and clockwise rotation of the chin would cause soft-tissue tension and consequently, the details of the underlying bone are further revealed. In the setback of the jaw and shortening and counterclockwise rotation of the chin, the soft-tissue tension is decreased and consequently, the details of the underlying bone are less revealed. The same movements with similar effects may affect the soft tissue of the chin following the movement of the mandible or maxillomandibular complex in concomitant orthosurgery and genioplasty [28], [29], [30], [31]. Future studies with larger sample sizes and longer follow-up periods are required to assess the effect of the location of osteotomy cut in the mandible on the esthetic results.

\section{Conclusions}

In general, irregularity in the inferior border of the mandible following conventional genioplasty is a common finding on radiographic and clinical examinations. The results of this study revealed that genioplasty with osteotomy line at the molar site had a significantly lower prevalence of step formation compared to genioplasty with osteotomy line at the premolar site on clinical inspection of the soft tissue of the chin. Furthermore, this approach was associated with a higher satisfaction rate of patients with the treatment outcome.

\section{Acknowledgments}

This work was performed in partial fulfillment of the requirements for a doctorate degree in General Dentistry (Osame Heidari), in Faculty of Dentistry, Kermanshah University of Medical Sciences, Kermanshah, Iran.

\section{References}

1. Gui L, Huang L, Zhang Z. Genioplasty and chin augmentation with medpore implants: A report of 650 cases. Aesthetic Plast Surg. 2008;32(2):220-6. https://doi.org/10.1007/s00266-007-9106-6 PMid:18158607

2. Morera Serna E, Scola Pliego E, Mir Ulldemolins N, Martínez Morán A. Treatment of chin deformities. Acta Otorrinolaringol Esp. 2008;59(7):349-58. https://doi.org/10.1016/ s2173-5735(08)70252-7

PMid: 18817718

3. Ferretti C, Reyneke JP. Genioplasty. Atlas Oral Maxillofac Surg Clin North Am. 2016;24(1):79-85.

PMid:26847515

4. Hofer D. Operation der prognathie und mikogenie. Dtsch Zahn Mund Kieferheilkd. 1942;9:121

5. Jones BM, Vesely MJ. Osseous genioplasty in facial aesthetic surgery-a personal perspective reviewing 54 patients. J Plast Reconstr Aesthet Surg. 2006;59(11):1177-87. https://doi. org/10.1016/j.bjps.2006.04.011 PMid:17046627

6. Park JY, Kim SG, Baik SM, Kim SY. Comparison of genioplasty using medpor and osteotomy. Oral Surg Oral Med Oral Pathol Oral Radiol Endod. 2010;109(2):e26-30. https://doi. org/10.1016/j.tripleo.2009.10.007

PMid:20123396

7. Strauss RA, Abubaker AO. Genioplasty: A case for advancement osteotomy. J Oral Maxillofac. 2000;58(7):783-7. https://doi. org/10.1053/joms.2000.7266

PMid: 10883694

8. Trauner $\mathrm{R}$, Obwegeser $\mathrm{H}$. The surgical correction of mandibular 
prognathism and retrognathia with consideration of genioplasty. Oral Surg Oral Med Oral Pathol. 1957;10(7):677-89. https://doi. org/10.1016/s0030-4220(57)80063-2

\section{PMid:13441284}

9. Lindquist CC, Obeid G. Complications of genioplasty done alone or in combination with sagittal split-ramus osteotomy. Oral Surg Oral Med Oral Pathol. 1988;66(1):13-6. https://doi. org/10.1016/0030-4220(88)90057-6

PMid:3165510

10. Chang EW, Lam SM, Karen M, Donlevy JL. Sliding genioplasty for correction of chin abnormalities. Arch Facial Plast Surg. 2001;3(1):8-15.

PMid: 11176712

11. Guyuron B, Raszewski RL. A critical comparison of osteoplastic and alloplastic augmentation genioplasty. Aesthetic Plast Surg. 1990;14(3):199-206. https://doi.org/10.1007/bf01578350 PMid:2399851

12. Mohammad S, Dwivedi CD, Singh RK, Singh V, Pal US. Medpore versus osseous augmentation in genioplasty procedure: A comparison. Natl J Maxillofac Surg. 2010;1(1):1-5. https://doi. org/10.4103/0975-5950.69147

PMid:22442541

13. Reed EH, Smith RG. Genioplasty: A case for alloplastic chin augmentation. J Oral Maxillofac Surg. 2000;58(7):788-93. https://doi.org/10.1053/joms.2000.7267

PMid:10883695

14. Kim YA, Steinbacher DM. Demineralized bone-fibrin sandwich for genioplasty. Aesthetic Plast Surg. 2014;38(4):755-8. https:// doi.org/10.1007/s00266-014-0362-y PMid:24938690

15. Lin J, Chen X. Modified technique of chin augmentation with MEDPOR forAsian patients. Aesthet Surg J. 2012;32(7):799-803. PMid:22942106

16. Ward JL, Garri JI, Wolfe SA. The osseous genioplasty. Clin Plast Surg. 2007;34(3):485-500. https://doi.org/10.1016/j. cps.2007.05.009

PMid:17692706

17. Bedoucha V, Boutin F, Frapier L. Impact of genioplasty during puberty on the upper airways. Int Orthod. 2015;13(4):421-35. https://doi.org/10.1016/j.ortho.2015.09.005 PMid:26520018

18. Kim GJ, Jung YS, Park HS, Lee EW. Long-term results of vertical height augmentation genioplasty using autogenous iliac bone graft. Oral Surg Oral Med Oral Pathol Oral Radiol Endod. 2005;100(3):e51-7. https://doi.org/10.1016/j. tripleo.2005.04.020

PMid: 16122647

19. Shaughnessy S, Mobarak KA, Høgevold HE, Espeland L. Longterm skeletal and soft-tissue responses after advancement genioplasty. Am J Orthod Dentofacial Orthop. 2006;130(1):8-17. https://doi.org/10.1016/j.ajodo.2004.11.035

PMid:16849066
20. Wolfe SA, Rivas-Torres MT, Marshall D. The genioplasty and beyond: An end-game strategy for the multiply operated chin. Plast Reconstr Surg. 2006;117(5):1435-46. https://doi. org/10.1097/01.prs.0000209461.99737.ed

PMid: 16641710

21. Kent JN, Zide MF, Kay JF, Jarcho M. Hydroxylapatite blocks and particles as bone graft substitutes in orthognathic and reconstructive surgery. J Oral Maxillofac Surg. 1986;44(8):597605. https://doi.org/10.1016/s0278-2391(86)80069-6

PMid:3016217

22. Rosen HM. Surgical correction of the vertically deficient chin. Plast Reconstr Surg. 1988;82(2):247-56. https://doi. org/10.1097/00006534-198808000-00006 PMid:2840684

23. Shaber EP. Vertical interpositional augmentation genioplasty with porous polyethylene. Int J Oral Maxillofac Surg. 1987;16(6):67881. https://doi.org/10.1016/s0901-5027(87)80052-8

PMid:3125265

24. Davis WH, Davis CL, Daly BW. Long-term bony and soft tissue stability following advancement genioplasty J Oral Maxillofac Surg. 1988;46(9):731-5. https://doi. org/10.1016/0278-2391(88)90181-4

PMid:3166043

25. Lye KW, Deatherage JR, Waite PD. The use of demineralized bone matrix for grafting during le fort I and chin osteotomies: Techniques and complications. J Oral Maxillofac Surg. 2008;66(8):1580-5. https://doi.org/10.1016/j.joms.2007.12.003 PMid: 18634943

26. Deshpande SN, Munoli AV. Osseous genioplasty: A case series. Indian J Plast Surg. 2011;44(3):414-21. https://doi. org/10.4103/0970-0358.90811 PMid:22279273

27. Hoenig JF. Sliding osteotomy genioplasty for facial aesthetic balance: 10 years of experience. Aesthetic Plast Surg. 2007;31(4):384-91 https://doi.org/10.1007/s00266-006-0177-6 PMid: 17549558

28. White JB, Dufresne CR. Management and avoidance of complications in chin augmentation. Aesthet Surg J. 2011;31(6):634-42.

PMid:21813876

29. Guyuron B, Kadi JS. Problems following genioplasty. Diagnosis and treatment. Clin Plast Surg 1997;24(3):507-14. PMid:9246516

30. Ewing M,RossRB. Softtissueresponsetomandibularadvancement and genioplasty. Am J Orthod Dentofacial Orthop. 1992;101(6):5505. https://doi.org/10.1016/0889-5406(92)70130-3 PMid:1598895

31. Van Sickels JE, Smith CV, Tiner B, Jones DL. Hard and soft tissue predictability with advancement genioplasties. Oral Surg Oral Med Oral Pathol Oral Radiol. 1994;77(3):218-21. https:// doi.org/10.1016/0030-4220(94)90288-7

PMid:8170650 